\title{
Regeneration and Healing
}

\author{
Letizia Zullo and Pamela Imperadore
}

\begin{abstract}
Cephalopods are animals endowed with a high regenerative potential. They can regenerate missing or injured structures such as the cornea, the shell, the arms and tentacles and even peripheral nerves and brain centers. As much as regeneration and healing cannot be considered as pathologies sensu stricto, they are always accompanied by conditions such as inflammation, tissue degeneration and potentially by infection. No treatments are currently available for any of these cases. Although they often get resolved autonomously, the early identification and monitoring of post-traumatic events is fundamental in the context of animal welfare.
\end{abstract}

\section{Keywords}

Tissue damage $・$ Traumatism $・$ Wound healing $・$ Regeneration process

\subsection{Introduction}

Wild animals often carry on their body signs of preexperienced traumatic events. Tissues and structures such as skin, fins and arms are reported to be subject to injury in the wild as well as in captivity, mainly due to capture and transport, autotomy, mating and competition (by conspecifics or predators) but also aggression and cannibalism (Budelmann 1998; Bush 2006, 2012; Hanlon et al. 1984).

In order to discriminate among mild to severe body damages, it is important to have a good understanding of the cephalopod physiology. As an example, abnormal body coloration can be due either to a superficial skin damage, which causes chromatophores expansion or skin retraction,

\section{Zullo (ه)}

Centre for Synaptic Neuroscience and Technology, Fondazione

Istituto Italiano Di Tecnologia, Genoa, Italy

e-mail: Letizia.Zullo@iit.it

P. Imperadore

Association for Cephalopod Research (CephRes), Naples, Italy

e-mail: p_imperadore@cephalopodresearch.org

P. Imperadore

Stazione Zoologica Anton Dohrn, Biology and Evolution of Marine Organisms, Naples, Italy or to a more severe damage to internal structures, such as the pallial or optic nerves and tracts, causing deafferentation of targeted organs. That is, alteration of the external appearance is not always the direct consequence of skin lesions but can be the secondary effect of an injury located elsewhere in the body. This aspect is particularly relevant in the context of animal welfare as it allows identifying the primary target to hit to ensure the animal wellness. In response to body damage, most of the cephalopods activate regenerating processes in various organs such as cornea, peripheral nerves, arm and tentacles (Imperadore and Fiorito 2018). Regeneration of the arms is particularly important as when one or more arms are damaged, the impairment of several functions, such as swimming, prey manipulation and posturing can occur (Tressler et al. 2014). This begins with a characteristic process of skin and tissue wound healing consistent within and across species (Fossati et al. 2013, 2015; Lange 1920; Shaw et al. 2016; Tressler et al. 2014).

Cephalopod skin has the vital role of protection against pathogens. The latter function becomes crucial when keeping animals in captivity, as it has been observed that severe ulcers can lead to death if untreated (Hanlon et al. 1984; Mather and Anderson 2007; Polglase 1980). It has also been noticed that undamaged squids adapt better than injured 
animals to temperature and salinity changes (Hanlon et al. 1983). Skin plays also an important role in cephalopods survival in their natural environment as they use body patterning, obtained through changes in color and shape of the skin, for concealment and communication (Messenger 2001; Packard 1988; Packard and Hochberg 1977). Hence, wounds and lesions have to be carefully monitored in captive animals to ensure a full recovery of their function and appearance and to avoid transferring possible infections to other animals (this can be exacerbated in closed water systems), as also suggested in the Guidelines for the Care and Welfare of Cephalopods in Research (Fiorito et al. 2015).

In this chapter, we will attempt at describing in details the healing and regeneration processes occurring at mantle and arms of Octopus vulgaris, a Cephalopods representative.

\subsubsection{Skin and Tissue Damage in Wild Animals: From Healing to Regeneration}

Traumatic events occurring in wild animals can cause alterations of several aspects of the body appearance. Animals can manifest from simple superficial skin lesions to partial or complete structure loss, as often occurs in the case of arms (Fig. 14.1).

As injured arms normally regenerate, it is not rare to see animals with one or more regenerating arms. Superficial wounds can have various extensions and can be very localized or distributed over the body, although small lesions are more frequently observed. Examples of wounds on mantle and on the eyeballs skin are reported in Fig. $14.1 \mathrm{a}^{\mathrm{I}}$ and $\mathrm{a}^{\mathrm{II}}$ where several small scratches are clearly visible. Arms can present unhealed wounds (Fig. 14.1b $\mathrm{b}^{\mathrm{I}}$ ) or regenerating arms (Fig. 14.1b $\mathrm{b}^{\mathrm{II}}$ and $\mathrm{b}^{\mathrm{III}}$ ) at various stages of regeneration depending on the time the traumatic event occurred. Lesions can be localized at any point along the arm although they are mostly found at its mid-terminal portion.

\subsection{Skin and Tissue Damage After Experimentally Induced Injury}

Wound healing in cephalopods has been investigated after experimentally induced mantle injury (Bullock et al. 1987; Polglase et al. 1983) and arm transection during the initial stages of arm regeneration (Féral 1988; Lange 1920; Shaw et al. 2016). In both cases, similar phenomena are observed. Indeed, even though arm regeneration involves recovery and regrowth of several tissues and structures (i.e., nerves, muscles, vessels, skin, etc.) it first requires healing of the wound. Healing starts with muscular contraction and epidermis in-folding (mainly connective tissue of the dermis) soon after injury (30 min). This phenomenon usually lasts for the first $12 \mathrm{~h}$, contributing to reducing the size of the lesion (Fig. 14.2). Here we present an exemplary case where a complete mantle wound closure is established as soon as 4 days after injury (Fig. 14.2 $\mathrm{a}^{\mathrm{I}}$ and $\mathrm{a}^{\mathrm{II}}$ ). Indeed, at 4 days only a thin line (red arrow), due to intense muscular contraction and epidermis in-folding, is still visible around the site of injury.
Fig. 14.1 Skin lesions in wild caught animals. a Wounds localized at the mantle (I) and around the eyeballs (II) (red asterisks); b examples of injured non-regenerating arm tip (I, red asterisk, scale bar $5 \mathrm{~mm}$ ) and regenerating arms (II, red asterisk, scale bar $6 \mathrm{~mm}$; III, red arrow). Regeneration can occur at any location of the arm depending only on the site of injury and will proceed towards the regeneration of a fully functional arm (II: early regenerating arm, III: late regenerating arm) (a)
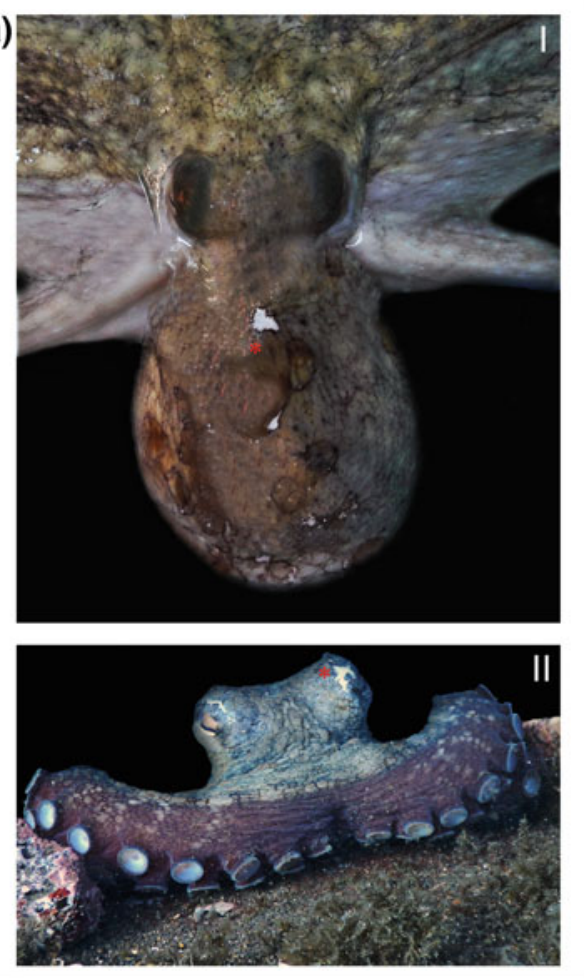

(b)
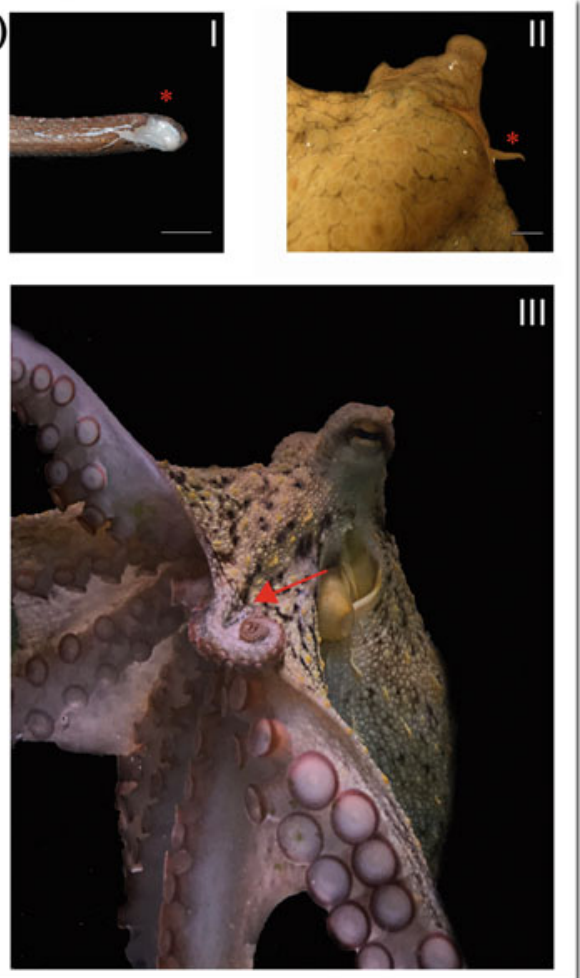

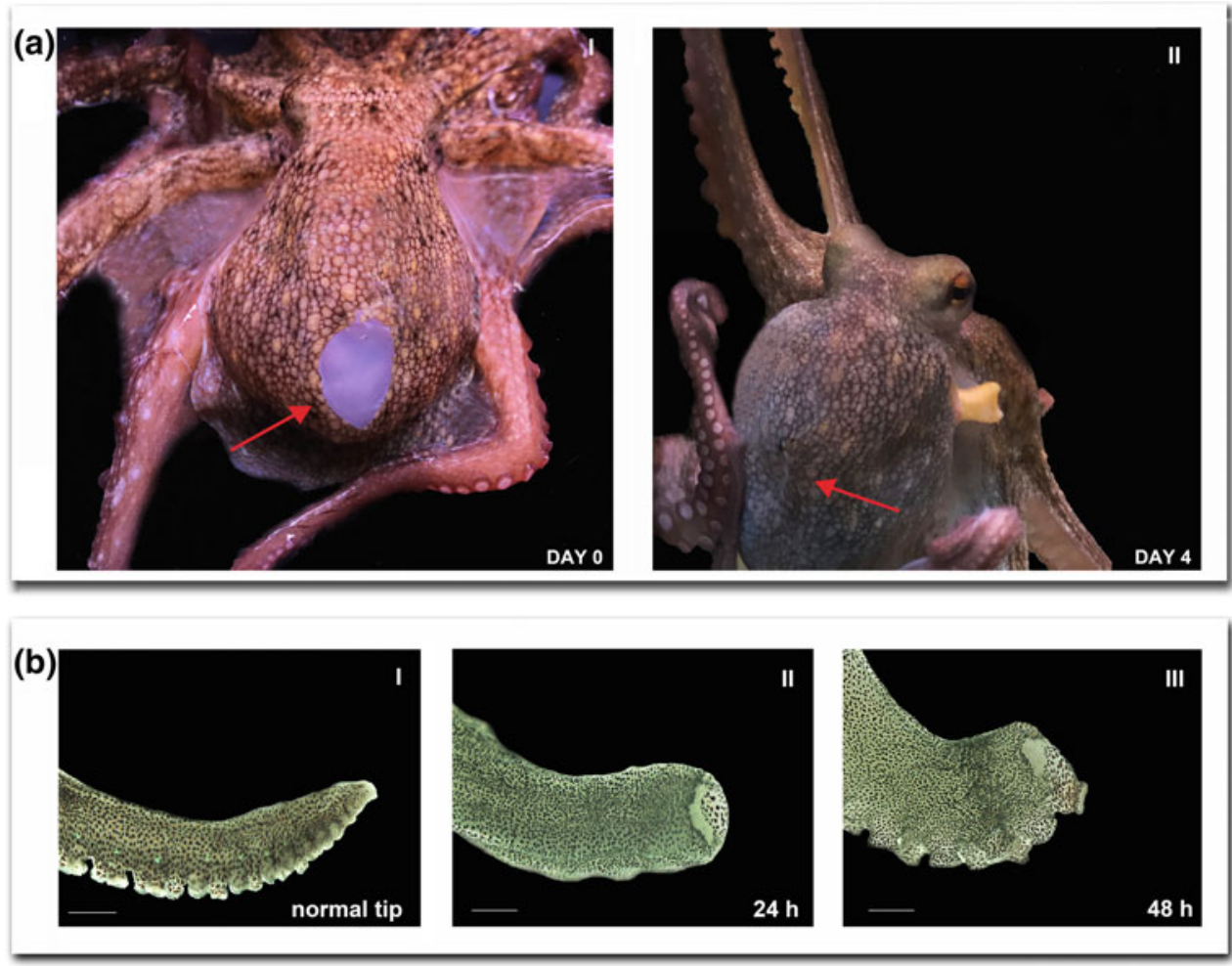

Fig. 14.2 Experimentally induced injury. a An animal showing a skin wound on the dorsal side of the mantle soon after experimental lesion (red arrow in I, Day 0). Four days later (II) the wound is almost completely closed, only a thin line (red arrow), due to intense muscular contraction and epidermis in-folding, is still visible around the site of injury. b Appearance of an arm tip uninjured (I), $24 \mathrm{~h}$ (II) and $48 \mathrm{~h}$

At the tissue level, hemorrhagic areas and hemocytes invade the wound, producing swelling in the central part of the wound which is mainly observed $12 \mathrm{~h}$ post injury as a result of increased hemocytes diapedesis. Hemocytes aggregates on the injury site (between day 1 and 3) and temporary protect the wound, also containing abundant extracellular matrix and likely vesicles and/or mucous. Later, blood cells stratify in several layers and change their shape from round to fusiform, providing a first dermal plug covering the whole surface of the wound. In the arm, this represents the primary blastema that is supposed to supply material for the regenerating tip. Epidermal cells round up 2 weeks post lesion, while 3 weeks later the epidermis thickness increases (for a detailed description see (Shaw et al. 2016)). Time of healing can be greatly affected by bacterial infection that determines delays in muscle contraction and epidermal migration; this eventually results in an incomplete closure of the wound. In addition, an increase in hemocytes release and in their activity is observed compared to not
(III) after lesion. Scale bars: $2 \mathrm{~mm}$. Soon after cut, the arm tip is interested by wound closure. 24 h' post injury, the majority of the exposed area is covered by skin (II). Two days post surgery (III) the wound is still visible but extremely reduced in size and suckers close to the lesion are brought toward the wound

infected wound. The majority of these cells become necrotic in proximity of the bacteria likely due to the effect of toxins released by the pathogens (Bullock et al. 1987).

Healing of the arm starts soon after the cut. In the example reported here, already $24 \mathrm{~h}$ ' post injury, the majority of the exposed area is covered by skin and 2 days post surgery the wound is still visible but extremely reduced in size; suckers close to the lesion are brought toward the wound (compare Fig. $14.2 b^{\mathrm{I}}, b^{\mathrm{II}}, b^{\mathrm{III}}$ ). The time required for the complete healing in the arm can go from less than $24 \mathrm{~h}$ up to 2 weeks on the base of several factors, mainly water temperature, animals' age and health status of the animals (Féral 1988; Lange 1920). In addition, healing appears also to depend on animal "self-abilities," as two different populations of healers have been identified for the common octopus, named slower and faster healers: in the latter case $80 \%$ of the wound is covered in 6 hours, $50-60 \%$ is observed instead for the slower group with modest increase in the following $18 \mathrm{~h}$ (Shaw et al. 2016). 


\subsection{Arm Regeneration}

We will now describe more in details the histological modifications occurring at tissue level following arm injury and regeneration (Fig. 14.3).

Immediately after healing, the process of arm regeneration starts and already 3 days after injury a little knob at the cutting point is visible. This later elongates forming a small protrusion. The first well-identifiable structure has the shape of a hook and appears around 17 days after the injury (Fig. 14.3a $\mathrm{a}^{\mathrm{I}}$ ). From histological analysis, a very thin layer of undifferentiated cells composes the first observed knob. A more defined and intensely proliferating "blastema" (bl) is then visible together with diffuse vascular components (v) at the arm tip (Fig. 14.3 $\mathrm{a}^{\mathrm{II}}$ ). This structure then disappears, tissues enter in a differentiation state and the process of histogenesis starts. At later stages (between 50 and 60 days usually) a complete structure is visible with the restoration of a typical non-injured arm (Fig. 14.3b $\mathrm{b}^{\mathrm{I}}$ ). At this stage both nervous $(\mathrm{g})$ and muscle elements $(\mathrm{m})$ become clearly visible and well-organized (Fig. 14.3b $\mathrm{b}^{\mathrm{II}}$ ) (Fossati et al. 2011, 2013; Lange 1920; Zullo et al. 2017).

A special case of regeneration is represented by the aberrant arm regeneration where the injured arm forms bi- or trifurcation. It is not uncommon in literature to find examples of aberrant regeneration of cephalopods arms and tentacles (Alejo-Plata and Méndez 2014; González and Guerra 2008; Toll and Binger 1991). Here we report a case where the regenerating stump developed a tripartite arm composed by structurally normal arms (Fig. 14.4).

\subsection{Pallial Nerve Degeneration and Regeneration}

A pair of pallial nerves, connecting the subesophageal mass of the CNS to the mantle, is involved in the control of breathing and in the mantle skin pattering. If both nerves are damaged, the animal dies soon after as breathing is completely abolished (Fredericq 1878); however, if only one of
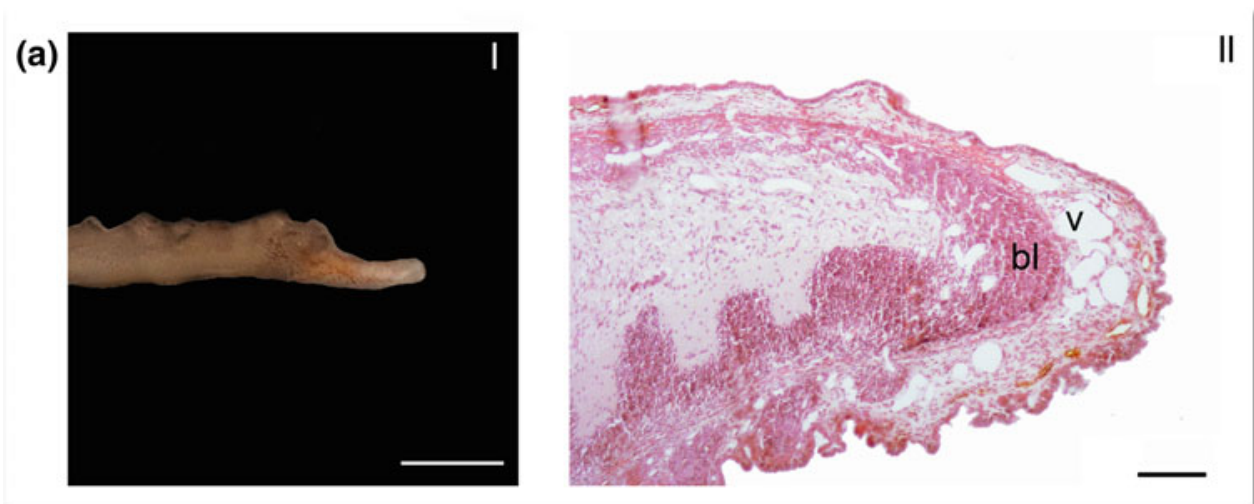

(b)
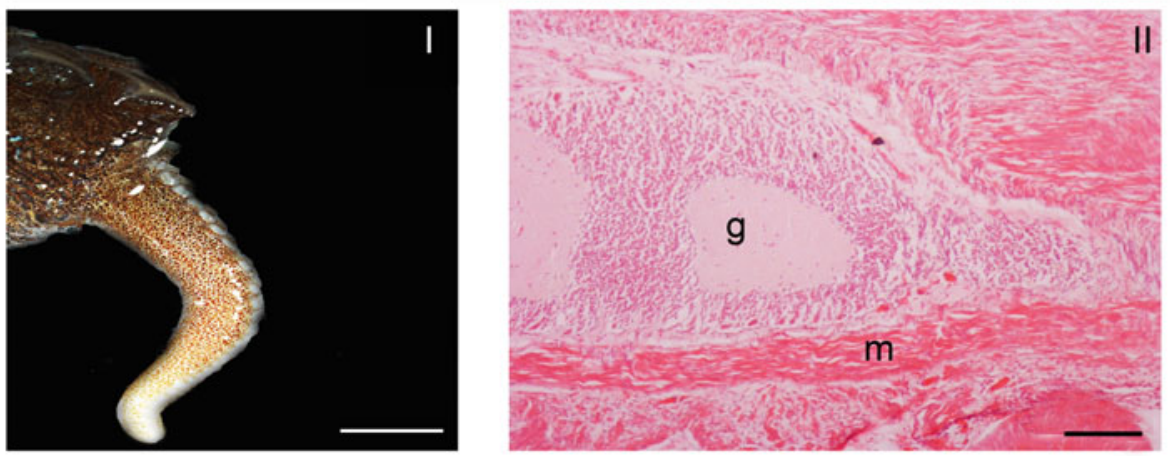

Fig. 14.3 Arm regeneration process. a Regenerating arm 17 days post injury. I: macroscopic image of the arm tip. Scale bar $5 \mathrm{~mm}$. II: Hematoxylin and eosin stained longitudinal section showing the blastemal areas (bl) at the arm tip rich of vascular components (v). Scale bar $50 \mu \mathrm{m}$. At this stage of regeneration, a hook-like structure is visible and the tip is much unorganized. b Regenerating arm 55 days post injury. I, macroscopic image of the arm tip. Scale bar: $5 \mathrm{~mm}$. II: Hematoxylin and eosin stained longitudinal section showing the well developed nervous (g: ganglia) and muscle (m) elements. Scale bar $100 \mu \mathrm{m}$. At this stage of regeneration, a normal arm structure is fully restored. Images $\mathrm{A}^{\mathrm{II}}, \mathrm{B}^{\mathrm{I}}$ and $\mathrm{B}^{\mathrm{II}}$ by courtesy of Dr. F. Carella 


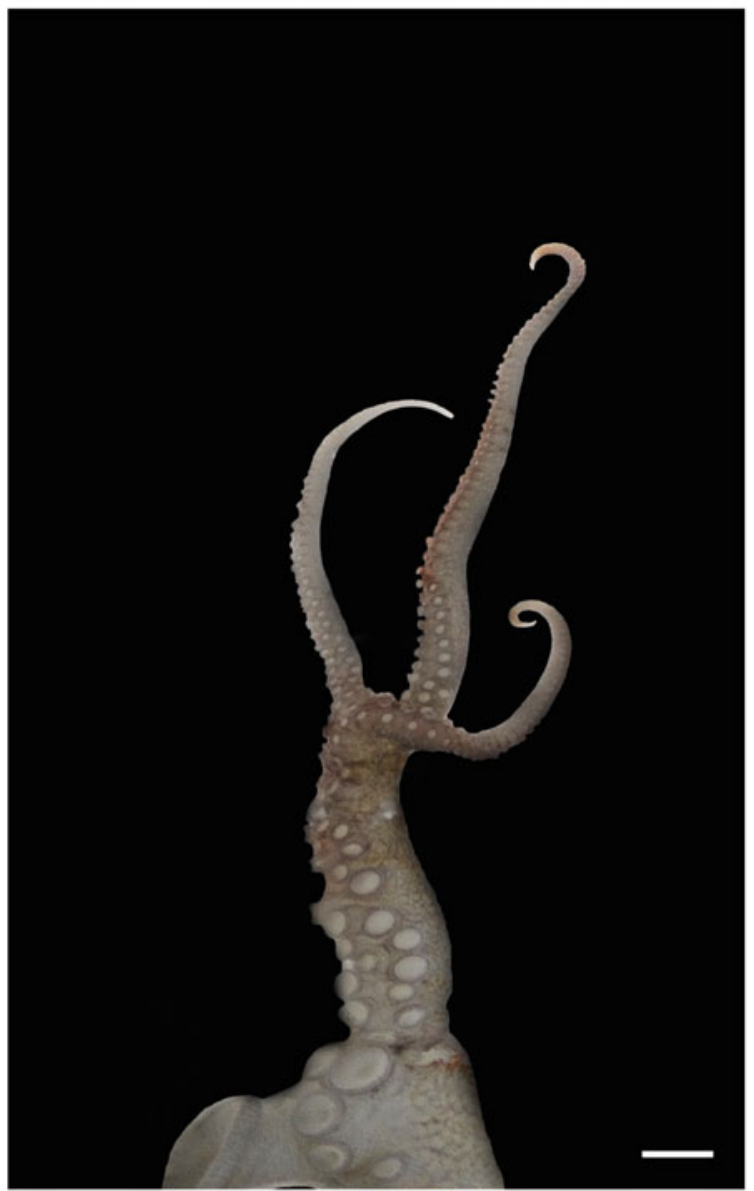

Fig. 14.4 Aberrant regeneration. Aberrant regeneration of an arm after lesion in the wild resulted in the formation of three morphologically normal tips. Scale bar $1 \mathrm{~cm}$. Source Dr. Panagiotis Grigoriou (CretAquarium, Heraklion, Greece)

the two is subjected to injury, the animal is not only able to survive, but it also regenerates the nerve, recovering the lost functions (Imperadore et al. 2017, 2018; Sanders and Young 1974; Sereni and Young 1932). This lesion has never been described as a naturally occurring phenomenon, such as arm regeneration. The few accounts available depict it as the effect of surgical operations, through pallial nerve cut or crush. This might be due to the particular location of the nerves, which are well-protected inside the mantle cavity. When one of these nerves is experimentally transected, two immediate effects are obtained: paling of the mantle skin and paralysis of the respiratory muscles on the side ipsilateral to the lesion (Fig. 14.5a, b) (Fredericq 1878; Imperadore et al. 2017; Sanders and Young 1974; Sereni and Young 1932).

Despite this loss of functions, the animal appears healthy and active soon after recovery from anesthesia. An increase in self-grooming actions close to the injured area is the only alteration that might occur after lesion (Imperadore et al. 2017).
Complete functional recovery requires several months, but usually already after 3 to 4 days post surgery the denervated skin undergoes some peculiar changes (Sanders and Young 1974). First we can observe skin paling due to chromatophore muscles relaxation, as neural control between CNS and periphery is lost (Sereni and Young 1932). This is followed by dark color waves randomly and quickly crossing the skin of the affected side of the mantle. These have been named "wandering clouds" and are due to a state of chromatophores hyperexcitability (Imperadore et al. 2017; Packard 1992; Sanders and Young 1974). Three to five days after injury, the skin on the side of lesion appears, at rest, homogeneously colored and, seven to fourteen days later it is able to match the color pattern of the contralateral side. However, paling immediately returns on the injured side during rapid pattern changes, such as prey attack or escape. This effect cannot be the result of a lack in functional regeneration but it is more likely driven by local effects involving skin photoreceptors (Imperadore et al. 2017).

At the microscopical level, lesions of the nerves induce inflammation followed by the formation of a scar between the two nerve stumps, hemorrhagic areas, and additional cicatricial tissues in the muscles damaged. These scars are mainly formed by hemocytes, which rush to the site of lesion and invade the nerve stumps. The scar separating the stumps does not represent a barrier, as fibers of the central stump (still connected to the CNS) start immediately to regenerate, reaching the opposite stump, with a growth rate between 7 and $18 \mu \mathrm{m} / \mathrm{h}$ (Fig. 14.5c). Peripheral stump regeneration is observed after 10-14 days post lesion, it appears initially characterized only by degenerative phenomena, with axons swelling and fragmentation (Imperadore et al. 2017; Sereni and Young 1932). Connective tissue in the nerve appears also to be involved in the process, sealing the cut stumps initially, shaping and driving them toward each other a few days later. Both, hemocytes and connective tissue actively proliferate at the cut nerve and interestingly neural elements have also been suggested start differentiating as soon as two weeks after lesion (Imperadore et al. 2017).

\subsection{Concluding Remarks}

Arms and mantle skin wounds of various severity and even arm loss are common events experienced by cephalopods in nature. Upon injury, animals can manifest a series of responses going from mild aberration of the body coloration and patterning to severe behavioral modifications. Injury is often only the "first hit" while "second hits" are determined by a variety of processes such as inflammation and infection of the wound occurring hereinafter that can alter not only the aspect but also the functionality of the damaged tissues. Body skin appearance have been listed within the potential 

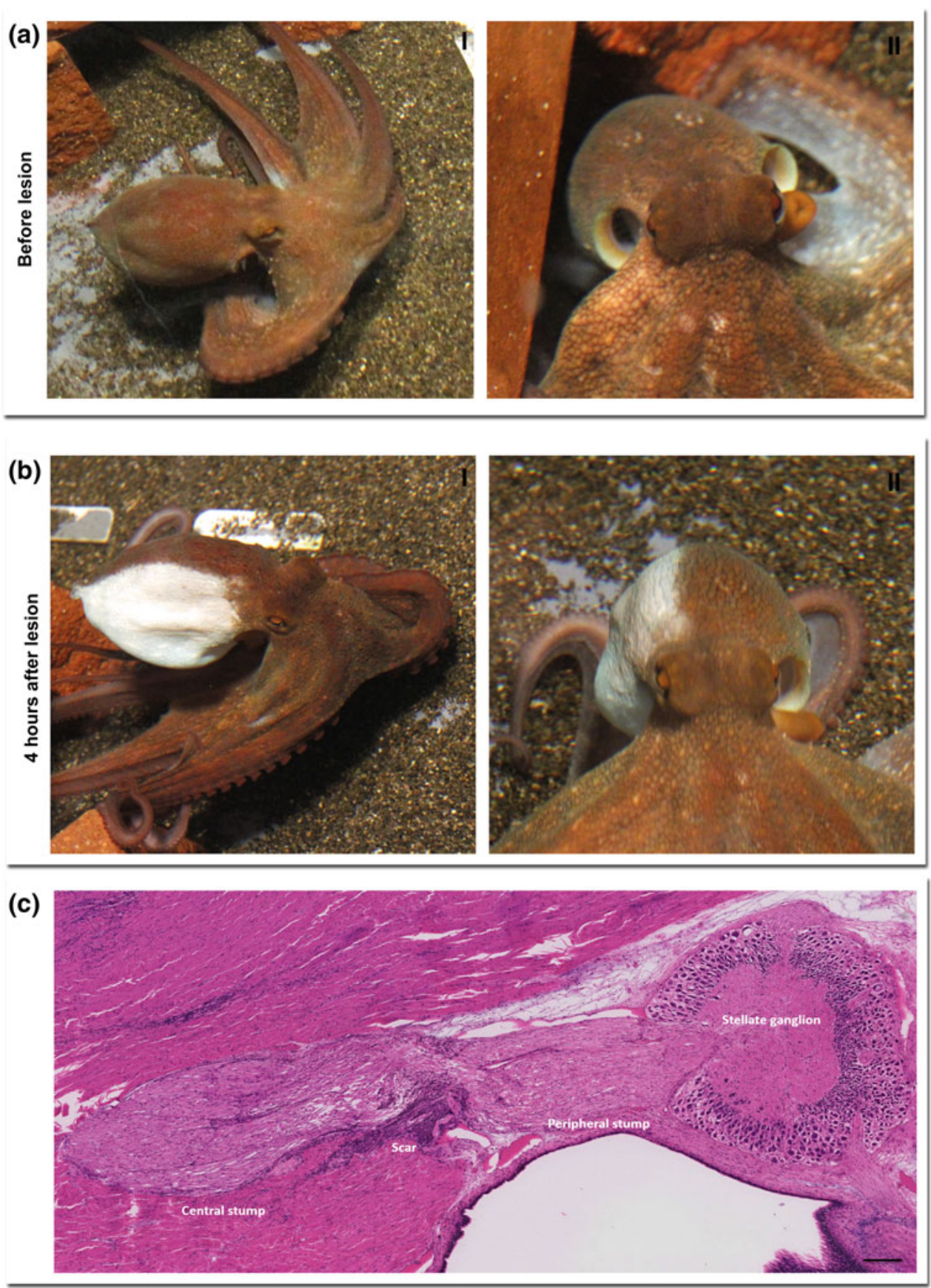

Fig. 14.5 Pallial nerve degeneration and regeneration. An animal before pallial nerve lesion (a) shows full ability in changing body pattern (I) and in controlling contraction of respiratory muscles on both sides of the mantle (II). Soon after lesion (b) the two functions are lost on the denervated side, which becomes completely pale (I) and flaccid (II). c Pallial nerve seven days post lesion presents a scar dividing the two nerve stumps (Central and Peripheral stumps), however the central stump is able to regenerate with fibers reaching the opposite side toward the stellate ganglion. Scale bar $0.2 \mathrm{~mm}$ indicators of health and welfare in cephalopods (Fiorito et al. 2015) and thus represents a feature that have to be constantly monitored especially in captive animals. Moreover, it is fundamental to provide a constant assessment of experimental animals undergoing surgical procedures as the occurrence of secondary effects induced by tissue incisions might take place even days after experimentation. For most of these events, no special treatment has yet been established. It is therefore important, in the context of animal welfare, to early identify the occurrence and progress of regeneration/degeneration processes to avoid the possible occurrence of unhealthy conditions in captive animals. 


\section{References}

Alejo-Plata MDC, Méndez OV (2014) Arm abnormality in Octopus hubbsorum (Mollusca: Cephalopoda: Octopodidae). Amer Malacolo Bull 32:217-219

Budelmann BU (1998) Autophagy in octopus. S Afri J Mar Sci 20:101-108

Bullock AM, Polglase JL, Phillips SE (1987) The wound healing and haemocyte response in the skin of the lesser octopus Eledone cirrhosa (Mollusca: Cephalopoda) in the presence of Vibrio tubiashii. J Zool 211:373-385

Bush SL (2006) Autotomy as a deep-sea squid defense. Integr Comp Biol 46:E19-E19

Bush SL (2012) Economy of arm autotomy in the mesopelagic squid Octopoteuthis deletron. Mar Ecol Progr Ser 458:133-140

Féral JP (1988) Wound healing after arm amputation in Sepia officinalis (Cephalopoda: Sepioidea). J Invert Pathol 52:380-388

Fiorito G, Affuso A, Basil J et al (2015) Guidelines for the Care and welfare of cephalopods in research-a consensus based on an initiative by CephRes, FELASA and the Boyd Group. Lab Anim 49:1-90

Fossati SM, Benfenati F, Zullo L (2011) Morphological characterization of the Octopus vulgaris arm. Vie Milieu 61:197-201

Fossati SM, Carella F, De Vico G, Et AL (2013) Octopus arm regeneration: role of Acetylcholine Esterase during morphological modification. J Exp Mar Biol Ecol 447:93-99

Fossati SM, Candiani S, Nodl MT et al (2015) Identification and expression of Acetylcholinesterase in Octopus vulgaris arm development and regeneration: a conserved role for ACHE? Mol Neurobiol 52:45-56

Fredericq L (1878) Recherches sur la Physiologie du poulpe commun. Arch Zool Exp Gen 7:535-583

González AF, Guerra A (2008) First observation of a double tentacle bifurcation in cephalopods. JMBA2 - Biodiversity Records: 1-6

Hanlon RT, Hixon RF, Hulet WH (1983) Survival, growth, and behavior of the loliginid squids Loligo plei, Loligo pealei, and Lolliguncula brevis (Mollusca: Cephalopoda) in closed sea water systems. Biol Bull 165:637-685

Hanlon RT, Forsythe JW, Cooper KM, Dinuzzo AR, Folse DS, Kelly MT (1984) Fatal penetrating skin ulcers in laboratory-reared octopuses. J Invert Pathol 44:67-83

Imperadore P, Fiorito G (2018) Cephalopod tissue regeneration: consolidating over a century of knowledge. Front Physiol 9:593. https://doi.org/10.3389/fphys.2018.00593
Imperadore P, Shah SB, Makarenkova HP, Fiorito G (2017) Nerve degeneration and regeneration in the cephalopod mollusc Octopus vulgaris: the case of the pallial nerve. Sci Rep 7

Imperadore P, Uckermann O, Galli R, Steiner G, Kirsch M, Fiorito G (2018) Nerve regeneration in the cephalopod mollusc Octopus vulgaris: label-free multiphoton microscopy as a tool for investigation J R Soc Interface 15 https://doi.org/10.1098/rsif.2017.0889

Lange MM (1920) On the regeneration and finer structure of the arms of the cephalopods. J Exp Zool 31:1-57

Mather JA, Anderson RC (2007) Ethics and invertebrates: a cephalopod perspective. Diseas Aqua Org 75:119-129

Messenger JB (2001) Cephalopod chromatophores: neurobiology and natural history. Biol Rev 76:473-528

Packard A (1988) The skin of cephalopods (coleoids): general and special adaptations. In: Trueman ER, Clarke MR (eds) The Mollusca, form and functions, vol 11. Academic Pres, pp 37-67

Packard A (1992) A note on dark waves (wandering clouds) in the skin of Octopus vulgaris. J Physiol 446:40

Packard A, Hochberg FG (1977) Skin patterning in Octopus and other genera. Symp Zool Soc Lond 38:191-231

Polglase JL (1980) A Preliminary Report on the Thraustochytrid(s) and Labyrinthulid(s) Associated with a Pathological Condition in the Lesser Octopus Eledone cirrosa. Bot Mar XXIII: 699-706

Polglase JL, Bullock AM, Roberts RJ (1983) Wound healing and the haemocyte response in the skin of the Lesser octopus Eledone cirrhosa (Mollusca: Cephalopoda). J Zool 201:185-204

Sanders GD, Young JZ (1974) Reappearance of specific colour patterns after nerve regeneration in Octopus. Proc R Soc London B, Biol Sci, p 186

Sereni E, Young JZ (1932) Nervous degeneration and regeneration in Cephalopods. Pubbl Staz Zool Napoli 12:173-208

Shaw TJ, Osborne M, Ponte G, Fiorito G, Andrews PL (2016) Mechanisms of wound closure following acute arm injury in Octopus vulgaris. Zool Letters 2:8

Toll RB, Binger LC (1991) Arm anomalies: cases of supernumerary development and bilateral agenesis of arm pairs in Octopoda (Mollusca, Cephalopoda). Zoomorphol 110:313-316

Tressler J, Maddox F, Goodwin E, Zhang Z, Tublitz NJ (2014) Arm regeneration in two species of cuttlefish Sepia officinalis and Sepia pharaonis. Invert Neurosci 14:37-49

Zullo L, Fossati SM, Imperadore P, Nodl MT (2017) Molecular determinants of cephalopod muscles and their implication in muscle regeneration. Front Cell Dev Biol 5:53
Open Access This chapter is licensed under the terms of the Creative Commons Attribution 4.0 International License (http://creative commons.org/licenses/by/4.0/), which permits use, sharing, adaptation, distribution and reproduction in any medium or format, as long as you give appropriate credit to the original author(s) and the source, provide a link to the Creative Commons licence and indicate if changes were made.
The images or other third party material in this chapter are included in the chapter's Creative Commons licence, unless indicated otherwise in a credit line to the material. If material is not included in the chapter's Creative Commons licence and your intended use is not permitted by statutory regulation or exceeds the permitted use, you will need to obtain permission directly from the copyright holder. 